\title{
Waiting for child developmental and rehabilitation services: an overview of issues and needs
}

Anton R. Miller

Children's andWomen's Health Centre of BC

Robert Armstrong

Aga Khan University, robert.armstrong@aku.edu

Louise C. Mâsse

University of British Columbia

Anne F. Klassen

McMaster University

Jane Shen

Child and Family Research Institute

See next page for additional authors

Follow this and additional works at: https://ecommons.aku.edu/eastafrica_fhs_mc_paediatr_child_health

Part of the Pediatrics Commons

\section{Recommended Citation}

Miller, A. R., Armstrong, R., Mâsse, L. C., Klassen, A. F., Shen, J., O’Donnell, M. E. (2008). Waiting for child developmental and rehabilitation services: an overview of issues and needs. Developmental Medicine \& Child Neurology, 50(11), 815-821.

Available at: https://ecommons.aku.edu/eastafrica_fhs_mc_paediatr_child_health/45 
Authors

Anton R. Miller, Robert Armstrong, Louise C. Mâsse, Anne F. Klassen, Jane Shen, and Maureen E. O’Donnell

This article is available at eCommons@AKU: https://ecommons.aku.edu/eastafrica_fhs_mc_paediatr_child_health/45 


\section{Waiting for child developmental and rehabilitation \\ services: an overview of issues and needs}

\author{
Anton R Miller* MB ChB FRCPC; \\ Robert W Armstrong MD PhD FRCPC; \\ Louise C Mâsse PhD, Department of Pediatrics, University \\ of British Columbia, Vancouver, BC; \\ Anne F Klassen DPhil, Department of Pediatrics, \\ McMaster University, Hamilton, ON; \\ Jane Shen MASc, Centre for Community Child Health \\ Research, Child and Family Research Institute; \\ Maureen E 0'Donnell MD MSc FRCPC, Department of \\ Pediatrics, University of British Columbia, Vancouver, BC, \\ Canada. \\ *Correspondence to first author at Centre for Community \\ Child Health Research, Room L408, Children's and Women's \\ Health Centre of BC, 4480 Oak Street, Vancouver, BC V6H \\ 3V4, Canada. \\ E-mail: amiller@cw.bc.ca
}

DOI: $10.1111 / j .1469-8749.2008 .03113 . x$

Published online September 222008

Concern about the length of time that children, young people, and families may have to wait to access assessment, diagnostic, interventional, therapeutic, and supportive child developmental and rehabilitation (CDR) services is widespread, but adequate data collection and research on this issue remain limited. We review key concepts and issues relevant to waiting for CDR services from the published literature, a national workshop devoted to this topic, and international experience. We conclude that gaps in data, evidence, and consensus challenge our ability to address the issue of waiting for CDR services in a systematic way. A program of research coupled with actions based on consensus-building is required. Research priorities include acquiring evidence of the appropriateness and effectiveness of different models of intervention and rehabilitation services, and documenting the experience and expectations of waiting families. Consensus-building processes are critical to identify, categorize, and prioritize 'sentinel' components of CDR service pathways: (1) to reduce the inherent complexity of the field; (2) to create benchmarks for waiting for these respective services; and (3) to develop definitions for wait-time subcomponents in CDR services. Collection of accurate and replicable data on wait times for CDR services can be used to document baseline realities, to monitor and improve system performance, and to conduct comparative and analytic research in the field of CDR services.
Wait times are an important barrier to access to publicly provided medical and other health-related services, and are of concern to service users, to providers, and to policy-makers. ${ }^{1-3}$ In Canada, wait times for joint replacement surgery, cardiac procedures, and imaging studies have become high-profile political issues, ${ }^{4,5}$ but less attention has been paid to wait times for health services for children. Furthermore, there has been minimal systematic study of wait times for what we refer to in this paper as child developmental and rehabilitation (CDR) services, a term that encompasses assessment, diagnostic, therapeutic, rehabilitation, and supportive services for children and young people with suspected or confirmed developmental delays and disabilities, and their families. (Note that we use the term 'rehabilitation' to include services aimed at restoring function, as well as 'habilitation' services for children who may never have established various functional skills.) There is a high level of concern among parents and professionals about waiting for CDR services in Canada, the UK, ${ }^{6,7}$ and other parts of the world, including Australia (M Wake, personal communication 2007) and South Africa (C Adnams, personal communication 2007); this concern is related to familiarity with evidence and opinion in favor of early intervention for affected children, anecdotal awareness that some children and families seem to wait for very long periods for developmental and rehabilitation services, and the perception that large variations in wait times exist between regions and jurisdictions. 
Our group has been addressing this gap through activities aimed at raising awareness, seeking and disseminating information, promoting dialogue among stakeholders, and developing an agenda for research and action in relation to wait times for CDR services. In the present paper, we provide an overview of the current state of knowledge, thinking, and practice in this area. The first three sections reflect the published literature, the views of stakeholders, and a sampling of current initiatives to address wait times in CDR services. In the final sections, we synthesize this information and propose actions for service providers, decision-makers, and researchers to address issues in waiting for CDR services.

\section{Literature review}

EARLY INTERVENTION AND NEUROSCIENCE LITERATURE

Informal review shows an extensive body of literature documenting the benefits of early intervention and possible harm associated with belated intervention for children with delayed and deviant development. This is particularly convincing for young children at psychosocial risk, ${ }^{8,9}$ and those with neurosensory impairments such as hearing and vision loss, ${ }^{10,11}$ but also for neurodevelopmental risk. ${ }^{12-15}$ The literature is bolstered by an emerging body of research into the phenomena of experience-induced neuroplasticity and early 'environmental programming' of brain and endocrine functioning. ${ }^{16-18}$ Although based mainly on animal models, this work provides biological evidence for long-term effects of early experience on neurodevelopment, and has clear relevance to human development and early intervention for infants and children 'at risk' ${ }^{19}$ The literature supports the need for 'early intervention'; however, with a few exceptions (such as evidence of better outcomes for hearing-impaired children who are identified and receive intervention within the first 6 months of life $\mathrm{e}^{10}$ ), the research leaves unaddressed questions such as whether waiting for an intervention service for 3 versus 6 months, for example, results in measurably poorer child or family outcomes.

WAIT TIMES AND WAIT LISTS FOR CDR SERVICES

For this part of the literature review we searched bibliographic databases (CINAHL, Medline, and PsycInfo) and websites (using Google) using as key search terms 'waitlist(s)', 'wait(ing) times', 'health service accessibility', 'triage', 'quality of care', and 'children or youth with disabilities/special needs'. Relatively few papers were found. Studies from Canada showed that children with developmental delays and disabilities in the Montreal area waited an average of 5 and 4 months to receive physiotherapy and occupational therapy services respectively; ${ }^{20}$ in another sample, half waited more than 7 and 11 months respectively, for these services. ${ }^{21}$ Factors associated with longer wait times included older child age $^{20,21}$ and residence in a suburban setting. ${ }^{20}$ In UK studies, Clow et al. described efforts to reduce wait times for an 'integrated hospital-community child health service' serving children with developmental, behavioral, and learning difficulties, ${ }^{6}$ and Preece and Mott used national standards for wait times for a multidisciplinary assessment of possible autism as a benchmark against which to evaluate the performance of a regional child development center. ${ }^{22}$

WAIT TIMES AND WAIT LISTS FOR OTHER HEALTH SERVICES Given the sparseness of literature on waiting for CDR services, we also performed a scoping review of the broader literature on waiting for health services (not limited to child health or CDR services), to identify key overview papers, grey literature, and web-based reports from agencies actively involved in wait-time and wait-list initiatives. Here we synthesize and present a range of points that were most robust in this literature and salient to our present focus.

Canadian surveys have shown that wait times of up to a few months are within an acceptable range to many people, suggesting that immediate action is not a public expectation, at least for elective specialty medical and surgical services. ${ }^{23}$ Studies of how long people wait for services have shown that many do receive service within a time-frame that many would consider reasonable, but some people seem to wait an inordinately long period of time, and that striking variations in wait times exist within jurisdictions or facilities. ${ }^{21,23}$

The literature recognizes that health and related services are organized and delivered in complex ways, with interplay between various aspects of the service system's performance, such as accessibility, appropriateness, effectiveness, and sustainability. ${ }^{24,25}$ The extent to which improvements in accessibility occur at the expense of other components (such as effectiveness) is unknown, although some reports suggest that such a trade-off does not necessarily occur. ${ }^{6}$ Nevertheless, the implication remains that measuring wait times for service in isolation from other measures or indicators may create a distorted and incomplete picture of service quality overall. $^{26}$ Another important general consideration is whether waiting patients are appropriately placed on wait lists for services, which in turn raises difficult questions about how decisions about assessment and treatment are made and whether they are based on evidence..$^{5,27}$

The literature also challenges the assumption that the solution to wait-time problems is through new resources that increase capacity. Additional resources do not necessarily lead to sustained improvements in timeliness of service. ${ }^{28,29}$ Conversely, an array of approaches other than adding new resources, including implementing prioritization strategies, achieving efficiencies in organizational processes, and flexibility in deployment of clinical staff, have been demonstrated to improve timeliness of service provision. ${ }^{3,6,28-32}$

In relation to collecting the data needed to document the extent of wait times across settings, and to track and evaluate the effects of initiatives aimed at improving wait-time data collection, the literature emphasizes certain prerequisites: (1) consensus in definition and measurement; ${ }^{23,33-35}$ (2) a comprehensive system of patient identification and registration, ${ }^{33,35}$ including the use of patient registries; ${ }^{36}$ and (3) systems for data storage and retrieval., ${ }^{44,34,37}$ To provide precision and enable comparability in measurement, the starting and ending points of certain components of wait times have been identified and applied within 'paths to care' models that have so far been formulated for elective surgical procedures and selected diagnostic imaging studies. ${ }^{35}$ Examples from the surgical pathway include: 'Wait 1', the time elapsed before primary care consultation; 'Wait 2', the period between date of referral from primary care to date of specialist (surgical) consultation; 'Wait 3', the time awaiting a decision to treat (which may include obtaining other consultations and tests); and 'Wait 4', the time between the date of decision to treat or date of booking an operation, and the date of surgery. ${ }^{35}$ Measurement of wait times requires not only a clear definition for each component, but also 
consistency in how these definitions are applied, and consensus on which components to include and report. ${ }^{23,33-35}$

Finally, three main types of activity were discernable in the general literature to deal with wait-time and wait-list problems, some of which we also observed in the CDR literature: (1) moves towards consensus-building and standardization of definitional and measurement issues in relation to wait times $;^{33,34}$ (2) efforts to rationalize and reduce wait times, including initiatives to create and implement benchmarks for waiting, ${ }^{4,27,34}$ and (3) initiatives to manage wait lists, including the development of systems to prioritize cases on a wait list. ${ }^{38}$ This literature includes efforts to define and operationalize relevant terms such as 'severity', 'urgency', and 'need' 39

\section{Stakeholder views and dialogue}

In August 2006, we convened a 1.5-day forum, 'Waiting for Child Development and Rehabilitation Services: A Research and Methodology Workshop', in Vancouver, BC, Canada, which brought together a diverse group of delegates comprising service providers, managers, and decision-makers from the field of child development and rehabilitation (including educational and social services), researchers from the fields of child health and health services research, and people with special expertise in wait-time and wait-list initiatives in Canada. The workshop provided overviews of research, measurement, and service delivery issues in the field of CDR, accounts of existing initiatives to address wait times and wait lists, and an opportunity for exchange of ideas between participants. Detailed notes were taken, major theme-areas were identified, and a summary report ${ }^{40}$ was produced. Following are the four key theme-areas that emerged during the workshop.

IMPORTANCE OF THE ISSUE OF WAITING FOR CDR SERVICES

Workshop participants affirmed that long waits for CDR services were of significant concern to parents and providers alike in light of three main considerations: (1) the evidence for early intervention for children with special needs; (2) the time-sensitive nature of the developmental period of childhood in relation to therapeutic interventions; ${ }^{4}$ and (3) the expectation that prolonged waiting will add to stress and uncertainty among parents and family members of a child awaiting diagnostic, assessment, and rehabilitation services, given the evidence that coping and adaptation are enhanced when families receive information and support through early intervention programs. ${ }^{41,42}$ Long wait lists may have a demoralizing effect on service providers, ${ }^{7}$ and may act as a deterrent to physicians referring children for rehabilitation services. ${ }^{43}$

CAVEATS AND CAUTIONS

The first of two main considerations was that the evidence to support specific interventions and care pathways in CDR is weak, and that expert consensus in this area remains undefined. For example, little is known about the relative efficacy of individual versus group therapy settings for children with speech-language delays, or whether ongoing rehabilitation of this kind requires the services of a specialist speech-language therapist. One implication of these gaps in knowledge and consensus is that it is hard to know whether children waiting for CDR services are waiting for the 'right' service. Another implication is that wait times may be affected dramatically by changes to service delivery models, though the effect of such changes on service effectiveness remains unknown. The second consideration was that a strong focus on wait times for services that are provided might distract from situations where services are needed but not provided.

NEED FOR DATA COLLECTION

Participants at the workshop felt that standardized data collection in relation to waiting for CDR services would be valuable for at least three reasons. First, it would allow us to obtain proper baseline documentation of how long people currently wait for various services. Second, such data would be a valuable tool in quality improvement efforts, allowing organizations and agencies to compare current wait times for particular services with agreed benchmarks, with their own historical performance, and with other jurisdictions. In these ways, proper collection of data allows greater accountability in provision of public services. Third, comparable data across settings can be used for research in jurisdictional studies of how variations in service organization and delivery can be related to variations in-patient or client outcomes, as well as system costs. This approach has been pioneered by the Canadian Neonatal Network in its evidence-based practice identification and change (EPIC) model. ${ }^{44,45}$

ISSUES WITH DATA COLLECTION

Having affirmed the value of proper data collection, participants at the workshop also identified a number of caveats to do with data collection. First, there are generic issues concerning collection of administrative data of any kind, such as the need for infrastructure and resources, issues of confidentiality, and concerns about the risks of manipulation of politically sensitive health data (such as wait-time data) in order to further agendas and influence decision-making regarding resource allocation. Second, there are specific challenges to the field of CDR services. The main one is the inherent complexity of this field. The fact that CDR services comprise many different services (sometimes for the same patient or client) provided in multiple settings, often across administrative sectoral boundaries (such as health, education, and social services) and by diverse providers, makes uniform data collection a complex challenge, especially when compared with the apparent simplicity of the Wait 1 and Wait 2 components of the service pathway of a patient who requires surgical replacement of a joint. There were also felt to be particular challenges to confidentiality if data on clients awaiting CDR services were to be pooled or shared across agencies and sectors, however desirable such an integrated approach might be.

Initiatives to reduce wait times: international experience In addition to describing what the literature and stakeholders say about issues related to wait times for CDR and other health services, we wanted also to present examples of what people are actually doing to deal with wait-time and wait-list pressures in the field of CDR service delivery. These 'case studies' are intended to be illustrative only, with no attempt made to be comprehensive or to critique the initiatives, given the limited data available.

AUTISM ASSESSMENT SERVICES IN BRITISH COLUMBIA, CANADA Children suspected of having an autism spectrum disorder in British Columbia used to wait 12 to 18 months 
for a diagnostic assessment at one of a handful of specialist referral centers that had the collective capacity to handle about 200 referrals per year. Supported by increased funding, a province-wide autism assessment network was established in 2002. A set of evidence-based standards and guidelines for the assessment and diagnosis of autistic disorders was formulated, which standardized as well as streamlined the diagnostic assessment process. Effort was invested in building regional capacity for autism assessments through creation of appropriately trained regional assessment teams, and in creating a shared, centralized data repository for children assessed through the network. Across the province, capacity for assessments has increased to 1100 per year, and average wait times for an assessment has fallen to below 6 months (K Kalynchuk, personal communication 2008; additional information available on request).

SPEECH-LANGUAGE ASSESSMENT AND THERAPY SERVICES IN HILLINGDON, UK The Speech and Language Therapy Department of the Hillingdon PCT NHS Trust in west London, UK, adjusted referral criteria to focus on preschool children and early intervention. The service delivery model was reorganized and reoriented toward group, rather than individual, therapy sessions, and emphasis was placed on training parents rather that working one to one with children. Wait times fell dramatically, from about 4 months to 4 to 6 weeks for initial assessment, and from 12 months to 6 to 12 weeks for therapy services, respectively (J Rockett, personal communication, 2008).

DEVELOPMENTAL ASSESSMENT SERVICES IN SOUTH CAROLINA, USA

Pediatricians at a pediatric tertiary care referral center in South Carolina developed an innovative procedure to deal with the problem of children referred with ill-defined developmental-behavioral problems having to wait long periods for assessment. ${ }^{46}$ In this model, a nurse practitioner and a social worker perform a fairly detailed but 'mid-level' assessment of referred cases, using a variety of standardized tools along with clinical interview and physical examination. Algorithms are used to guide recommendations for further evaluation or interventions. In pilot testing of this new procedure, wait times for comprehensive developmental-behavioral assessment at the center decreased from 168 to 26 days. ${ }^{46}$

\section{Synthesis}

There have been few systematic efforts to study the extent, determinants, and effects of wait times for CDR services for children and families. This is despite direct and indirect evidence to support the need for prompt and early intervention, and the fact that timely access to appropriate health and related services is considered to be one of a number of key goals in a high-quality service system. ${ }^{5,24}$ Stakeholders in the CDR field support the need for better information in this area, including collection of data on wait times using standardized methods, while at the same time expressing hesitation about some aspects of data collection. There is also concern that professional recommendations for the most appropriate type of rehabilitative or remedial interventions in terms of amount, format, or setting, are rarely evidence-based, raising concerns about whether children and families are waiting for the 'right' service. However, decision-making in many aspects of health-related service provision is not strongly evidencedbased, and a moral and clinical imperative remains to provide what appear to be the most appropriate services and supports in a timely manner. Because we also lack evidence about the relative efficacy of different services and approaches, the possibility exists that wait times can be reduced by changes to service delivery models or pathways, an effect that we have observed in specific examples of innovation in practice. However, whether the adoption of new models is associated with changes in service effectiveness in addition to changes in wait times, has not been adequately addressed.

The issue of waiting for CDR services needs to be addressed in a systematic way, but there are gaps in information, evidence, and consensus that make it challenging to address these issues. Coming to grips with these issues will require a program of research that addresses knowledge gaps and methodological issues as identified in this overview, coupled with a program of actions based on consensusbuilding.

\section{Priorities for research and action}

RESEARCH NEEDS

Clearly, lack of evidence for the appropriateness and effectiveness of different models of (early) intervention and rehabilitation services is an important concern. Research to investigate different models is both warranted and required, with attention to a range of outcome indicators at the child and family levels, which include evidence of effectiveness and satisfaction, and at the system level, including wait times and costs. Assuming that wait lists for services will probably never be wholly eradicated, research should also be directed toward the experience and expectations of waiting for CDR services on the part of parents. Such research should focus on what is being done while waiting for definitive services, what could be done to improve the situation during periods of waiting, and the needs and expectations of families while they are waiting. Research should also examine whether waiting for services presents more risk for some children in some families in some situations.

Data on wait times, if collected in a careful and standardized way, can be instrumental in advancing research into the delivery, organization, and quality of CDR services. Even though it might be difficult to organize classical randomized trials of different models of service provision, alternatives such as pragmatic clinical trials ${ }^{47,48}$ are possible in this area. Opportunities also exist to take advantage of natural variation in service provision in cross-jurisdictional studies and to develop innovative ways of studying this variation in relation to wait times either as an outcome itself or as a predictor of clinical and patient and family experience of outcomes. Collaborative networks using common diagnostic, process, and outcome measures can have a tremendously important impact even without randomized trials, as exemplified by the Canadian Neonatal Network's EPIC model. ${ }^{4,45}$ In the field of child development and rehabilitation in Canada, networks of service-providing agencies and researchers are emerging ${ }^{49,50}$ but are not yet collaborating in formal studies of how naturalistic variation in services may relate to variations in outcomes. 
ACTION-BASED INITIATIVES TOWARDS SYSTEMIC ACCOUNTABILITY Complexity in the delivery of CDR services has been flagged as an obstacle to data collection in this field. This complexity can be dealt with by focusing on 'sentinel' conditions, populations, or elements within particular service pathways or scenarios, that are (1) deemed to be most important and (2) common or core elements across settings and agencies. Examples might be the time from referral to initial assessment of a young child with speech delay, the time from initial assessment to definitive assessment, if applicable, and the time from assessment to child and family obtaining services or information that the family perceives as germane to the identified problem. A consensus-building process can be used to identify important clinical scenarios and then core elements within these scenarios. In an initiative to reduce wait times that has been positively received by the federal government of Canada, a national network of pediatric surgeons representing the full range of surgical subspecialties recently worked effectively to categorize the array of surgical intervention types for children, and then to define benchmarks for how long a child should have to wait for each type. ${ }^{51}$

Another need that can be addressed through consensus-building is the development of standardized definitions for various aspects and components of waiting, so that data collected from different sites can be compared and combined. It is also important to define and discriminate between undesirable and remediable administrative types of waiting, and waits attributable to patient convenience and preference. We see consensus-building processes as critical to categorize and prioritize CDR services, to create benchmarks for waiting for these respective services, and to develop definitions for the various wait-time subcomponents that occur in CDR services.

We have no specific solutions to concerns about data integrity and confidentiality in CDR services, but point out that many agencies already collect data about their clients and services. The issues for CDR services may have more to do with safeguards around transferring or sharing data, if data were going to be aggregated within a regional reporting mechanism that crosses traditional agency or administrative sectoral boundaries, as well as the need to ensure responsible use and interpretation of the data. Regional registries for children referred to developmental services might be a useful vehicle to promote data collection and to deal with confidentiality issues. To ensure responsible use of collected data, it seems advisable that the definitions, assumptions, context, and aims of data collection and reporting be set out in a transparent way and agreed by the main stakeholders at the outset, with policies in place to guard against arbitrary changes of definitions or service procedures once data collection has commenced.

\section{Conclusion}

The existence of knowledge gaps in relation to provision of CDR services should not imply that nothing can be done to address issues of children and families waiting for CDR services. The confluence of a number of factors mandates the adoption of a systematic and rigorous approach to ensure accountability, equity, and fairness in the provision of public services. These factors are a current lack of objective information on how long children and parents wait for these services, the lack of reasonable benchmarks for wait times for various services, anecdotal information that some children in some areas are waiting long periods for certain services, and the evidence in favor of early and prompt intervention. In addition, parents want and benefit from identification, information, support, and intervention for disabling conditions in their children; ${ }^{9,41,42,52,53}$ and there appears to be a moral obligation to provide information and support in a timely way, once a neurodevelopmental disorder has been diagnosed. In some countries, federal regulations dictate that early intervention services be provided in a timely way to young children with developmental delays and disabilities. $^{54}$

Imperatives to provide services in a timely way, and to document how providers and agencies are performing in this regard, exist alongside the need for a wide-ranging program of research into the effectiveness of the specific type and format of interventions offered and recommended for young children with developmental delays and disabilities and their families. The research program should proceed in parallel with efforts to measure, document, and set benchmarks for the services that we currently recommend and use, starting with interventions and service delivery models for which evidence is currently available. In the absence of strong evidence we need to rely on strategies such as consensus panels to determine what are required services and therefore warrant consideration for wait-time monitoring.

We have a much greater understanding than ever before of the capacity to influence the 'hard wiring' of the brain during development, especially in the early years. ${ }^{8,19}$ It is incumbent on us to build the evidence base of what works to support development and to understand the variety of strategies that might ensure children and their families get the services that they need when they need them. Measuring, reporting, and researching wait times can be a central platform for our further support and advocacy for this population of children and families.

Accepted for publication 29th May 2008.

\section{Acknowledgements}

The authors gratefully acknowledge financial support for the workshop 'Waiting for Child Development and Rehabilitation Services: A Research and Methodology Workshop' from the Institute of Human Development, Child and Youth Health of the Canadian Institutes of Health Research, and the Provincial Health Services Authority of British Columbia. Anton Miller's contribution to this work was assisted by support from the Sunny Hill Foundation. Anne Klassen is the recipient of a Canadian Institute of Health Research career award and Michael Smith Foundation for Health Research Scholar Award. Louise Mâsse is the recipient of a Michael Smith Foundation for Health Research Senior Scholar award. The authors gratefully acknowledge Dr Peter Rosenbaum's helpful review of the manuscript.

\section{References}

1. Aday LA. Economic and noneconomic barriers to the use of needed medical services. Med Care 1975; 13: 447-56.

2. Health Council of Canada. A background note on benchmarks for wait times. Toronto, ON: Health Council of Canada, 2005. 
3. Siciliani L, Hurst J. Tackling excessive waiting times for elective surgery: a comparative analysis of policies in 12 OECD countries. Health Policy 2005; 92: 201-15.

4. Postl BD. Final report of the federal advisor on wait times. Ottawa, ON: Health Canada, 2006

5. Health Council of Canada. Wait times. An excerpt from health care renewal in Canada: clearing the road to quality. Toronto, ON: Health Council of Canada, 2006.

6. Clow D, Mustafa A, Szollar J, Wood N, Reid J, Sinden S. Reducing waiting times associated with an integrated child health service. J R Soc Health 2002; 122: 245-50.

7. Keating D, Syrmis M, Hamilton L, McMahon S. Paediatricians: referral rates and speech pathology waiting lists. J Paediatr Child Health 1998; 34: 451-55.

8. Center on the Developing Child at Harvard University. (2007) A science-based framework for early childhood policy: using evidence to improve outcomes in learning, behavior, and health for vulnerable children. http://www.developingchild. harvard.edu/content/downloads/Policy_Framework.pdf (accessed 02 July 2008).

9. Anderson LM, Shinn C, Fullilove MT, et al. The effectiveness of early childhood development programs. A systematic review. Am J Prev Med 2003; 24: 32-46.

10. Yoshinaga-Itano C, Sedey AL, Coulter DK, Mehl AL. Language of early- and later-identified children with hearing loss. Pediatrics 1998; 102: 1161-71.

11. Javitt J, Cas RD, Chiang Y. Cost-effectiveness of screening and cryotherapy for threshold retinopathy of prematurity. Pediatrics 1993; 91: 859-66.

12. Guralnick MJ. Effectiveness of early intervention for vulnerable children: a developmental perspective. Am J Ment Retard 1997; 102: 319-45.

13. Warfield ME. A cost-effectiveness analysis of early intervention services in Massachusetts: Implications for policy. Educational Evaluation and Policy Analysis. 1994; 16: 87-99.

14. Shonkoff JP, Hauser-Cram P. Early intervention for disabled infants and their families: a quantitative analysis. Pediatrics 1987; 80: 650-58

15. Majnemer A. Benefits of early intervention for children with developmental disabilities. Semin Pediatr Neurol 1998; 5: 62-69.

16. Meaney MJ, Szyf M. Maternal care as a model for experiencedependent chromatin plasticity? Trends Neurosci 2005 ; 28: 456-63.

17. Szyf M, McGowan P, Meaney MJ. The social environment and the epigenome. Environ Mol Mutagen 2008; 49: 46-60.

18. Kaffman A, Meaney MJ. Neurodevelopmental sequelae of postnatal maternal care in rodents: Clinical and research implications of molecular insights. J Child Psychol Psychiatry 2007; 48: 224-44.

19. Shonkoff JP, Phillips D, editors. From neurons to neighborhoods: the science of early childhood development. Washington, DC: National Academy Press, 2000.

20. Feldman DE, Champagne F, Korner-Bitensky N, Meshefedjian G. Waiting time for rehabilitation services for children with physical disabilities. Child Care Health Dev 2002; 28: 351-58.

21. Grilli L, Feldman DE, Swaine B, Gosselin J, Champagne F, Pineault R. Wait times for paediatric rehabilitation. Healthcare Policy 2007; 2: 1-17.

22. Preece PM, Mott J. Multidisciplinary assessment at a child development centre: do we conform to recommended standards? Child Care Health Dev 2006; 32: 559-63.

23. Canadian Institute for Health Information. Waiting for Health Care in Canada: What We Know and What We Don't Know. Ottawa, ON: Canadian Institute for Health Information, 2006.

24. Institute of Medicine. Crossing the quality chasm: a new health system for the 21st century. Washington, DC: National Academies Press, 2001.

25. Canadian Institute for Health Information. The health indicators project: the next 5 years. Report from the Second Consensus Conference on Population Health Indicators. Ottawa, ON: Canadian Institute for Health Information, 2005.

26. Rotstein DL, Alter DA. Where does the waiting list begin? A short review of the dynamics and organization of modern waiting lists. Soc Sci Med 2006; 62: 3157-60.
27. Abou-Rizk Z, Fafard P, Lafrance T, McIntosh T. The taming of the queue IV: new frontiers of wait time measurement, monitoring and management. Ottawa, ON: Canadian Policy Research Networks, 2007.

28. Hanning M. Maximum waiting-time guarantee - an attempt to reduce waiting lists in Sweden. Health Policy 1996; 36: 17-35.

29. Sanmartin C, Shortt SED, Barer ML, Sheps S, Lewis S, McDonald PW. Waiting for medical services in Canada: lots of heat, but little light. CMAJ 2000; 162: 1305-10.

30. Strindhall M, Henriks G. How improved access to healthcare was successfully spread across Sweden. Qual Manag Health Care 2007; 16: 16-24.

31. Nolan TW, Schall MW, Berwick DW, Roessner J. Breakthrough Series Guide: reducing delays and waiting times throughout the healthcare system. Boston, MA: Institute for Healthcare Improvement, 1996.

32. Murray M, Berwick DM. Advanced access: reducing waiting and delays in primary care. JAMA 2003; 289: 1035-40.

33. Fooks C. The taming of the queue: wait time measurement, monitoring and management. Ottawa, ON: Canadian Policy Research Networks, 2004.

34. McIntosh T. The taming of the queue: wait time measurement, monitoring and management. Ottawa, ON: Canadian Policy Research Networks, 2005.

35. Sanmartin CA, Steering Committee of the Western Canada Waiting List Project. Toward standard definitions for waiting times. Healtbc Manage Forum 2003; 16: 49-53.

36. Cardiac Care Network of Ontario (CCN). Wait list statistics. http://www.ccn.on.ca/index.cfm?fuseaction $=\mathrm{tm} \& \mathrm{tm}=17 \&$ ts $=0 \& \mathrm{tsb}=0$ (accessed 02 July 2008).

37. Health Council of Canada. Health care renewal in Canada: measuring up? Toronto, ON: Health Council of Canada, 2007.

38. Noseworthy TW, McGurran JJ, Hadorn DC, Steering Committee of the Western Canada Waiting List Project. Waiting for scheduled services in Canada: development of priority-setting scoring systems. J Eval Clin Pract 2003; 9: 23-31.

39. Hadorn DC, Steering Committee of the Western Canada Waiting List Project. Setting priorities for waiting lists: defining our terms. CMAJ 2000; 163: 857-60.

40. Children and Youth with Disabilities in Society (CYDiS). Waiting for child development and rehabilitation services: a research and methodology workshop. Summary Report (2006). http://www.cfri.ca/our_research/programs crosscutting_theme/community_child_health/documents/ WaitingWorkshopSummaryReport_Final2006.pdf (accessed 02 July 2008).

41. Pain H. Coping with a child with disabilities from the parents' perspective: the function of information. Child Care Health Dev 1999; 25: 299-312.

42. Pelchat D, Bisson J, Ricard N, Perreault M, Bouchard JM. Longitudinal effects of an early family intervention programme on the adaptation of parents of children with a disability. Int J Nurs Stud 1999; 36: 465-77.

43. Scott FG, Lingaraju S, Kilgo JL, Kregel J. A survey of pediatricians on early identification and early intervention services. J Early Intervent 1993; 1\%: 129-38.

44. Canadian Neonatal Network. Evidence-based practice identification \& change (EPIC). http://www.canadianneonatalnetwork.org/project.shtml (accessed 02 July 2008).

45. MacNab YC, Qiu ZG, Gustafson P, Dean CB, Ohlsson A, Lee SK. Hierarchical Bayes analysis of multilevel health services data: a Canadian neonatal mortality study. Health Serv Outcomes Res Metbodol 2004; 5: 5-26.

46. Kelly D. Mid level developmental-behavioral pediatric assessments. Behavioral developments (Society for Developmental \& Behavioral Pediatrics Newsletter) (2007). http:// www.sdbp.org/newsletter/SDBPFall2007.pdf (accessed 02 July 2008).

47. Roland M, Torgerson DJ. Understanding controlled trials: what are pragmatic trials. BMJ 1998; 316: 285-86.

48. Tunis SR, Stryer DB, Clancy CM. Practical clinical trials: increasing the value of clinical research for decision making in clinical and health policy. JAMA 2003; 290: 1624-32.

49. Children's Rehabilitation Research Network (CRRN). http:// www.crrn.ca/about.htm (accessed 02 July 2008). 
50. Canadian Network for Child and Youth Rehabilitation (CNCYR). http://www.caphc.org/partnerships_cncyr.html (accessed 02 July 2008).

51. National Child and Youth Health Coalition. 'Children wait too'. National paediatric surgical wait times strategy. Final report. Ottawa, ON: National Child and Youth Health Coalition, 2006.

52. Bailey DB Jr, Skinner D, Warren SF. Newborn screening for developmental disabilities: reframing presumptive benefit. Am J Public Health 2005; 95: 1889-93.
53. Bailey DB Jr, Hebbeler K, Spiker D, Scarborough A, Mallik S, Nelson L. Thirty-six-month outcomes for families of children who have disabilities and participated in early intervention. Pediatrics 2005; 116: 1346-52.

54. US Department of Education. Individuals with disabilities Education Improvement Act of 2004. Washington, DC: Government of United States, 2004; Public Law 108-446 108th Congress. http://idea.ed.gov/download/statute.html (accessed 02 July 2008).

\section{5th Annual Update Symposium on Clinical Neurology and Neurophysiology}

16 - 17 February 2009, Tel Aviv, Israel

Deadline for abstracts: 15 November 2008 (300 words)

For further details contact: Rachel Weiner, ISAS International Seminars

Tel: ++972-2-6520574; Fax: ++972-2-6520558; E-mail: conventions@isas.co.il

http:// www.neurophysiology-symposium.com 